\title{
Author and Editor Directory
}

Maximilian Bergengruen German Studies, Institut für Germanistik, KIT - Karlsruher Institut für Technologie

Angela Gencarelli German Studies and Literary Cultures, Institut für Geschichtswissenschaft und Literarische Kulturen, Leuphana Universität Lüneburg

Aura Heydenreich German Studies and Comparative Literature, Department Germanistik und Komparatistik, Universität Erlangen-Nürnberg

Lutz Kasper Physics Department, University of Education Schwäbisch Gmünd

Nikola Kompa Theoretical Philosophy, Department of Philosophy, University of Osnabrück

Jay A. Labinger Chemistry, Beckman Institute, California Institute of Technology

Lukas Mairhofer Department of Applied Mathematics and Physics, FH Technikum Wien

Bernadette Malinowski German Studies and Comparative Literature, Philosophische Fakultät, Technische Universität Chemnitz

Ignatius McGovern School of Physics, Trinity College Dublin

Klaus Mecke Theoretical Physics, Universität Erlangen-Nürnberg

Stephan Mühr German Studies and Culture Theory, University of Pretoria

Kieran Murphy French Studies and Comparative Literature, University of Colorado Boulder

Clemens Özelt German Studies, Deutsches Seminar, Universität Zürich

Arkady Plotnitsky Department of English, Purdue University

Winfried Thielmann German Linguistics, Technische Universität Chemnitz

Dirk Vanderbeke English Studies, University of Jena

Giovanni Vignale Department of Physics and Astronomy, University of Missouri-Columbia 
